\title{
Reverse Cowgirl by McKenzie Wark
}

\author{
Review by J Inscoe \\ University of Maryland Baltimore County
}

Wark, McKenzie. Reverse Cowgirl. Semiotext(e), 2020.

A treatise to non-existence, McKenzie Wark's Reverse Cowgirl details a gender transition in absentia. Her lubricious romp through an America coming to terms with queer life frames a discussion of bodily morphology, an identity formation through somatic disformation. Sex. Anal sex. And lots of it.

Reverse Cowgirl is less about transition than it is about being, a being discovered through a body turned inside out, sexed into non-existence, de-gendered through an intensely gendered act. The absence of words-emotional labor, gas-lighting, femme, trans-dominates the stage. As Wark reflects, "I felt like her faggot girl. I knew no words for this" (p. 43). Wark crucially derives an identity from acts out of time, out of existence, and out of language-our verbal system of signs, that is. The visual looms large in the tenuous struggle to inverse the skin, less bending over backwards than bending over forward.

The reader may find Wark's genre untenably slippery: it is an erotic autobiography, and yet a biological autoeroticism, a discovery of the fuckable self through the (s)exploitation of "this itchy flesh" (p. 180). One chapter in particular, "User Manual," declares Reverse Cowgirl to be not a "coming of age" but an "age of cum" (p. 62), an extravagant history of desire-and the act of consummating that desire-as itself a syntax of the self. (If one grows tired of the insistent antithesis, clearly they haven't lived it.)

It is also a critique of, increasingly, selectively-sanctioned queer (and class) identity through the late 20th Century: from the "clones" or "straight gays," uber-masculine simulations of the heterosexual man; to the flower-child lesbians, antipodes to the BDSM lesbians; to the aesthetes, simulations of the upper hetero-eschelon, the accepted homosexual. "The non-straight world," Wark observes, "was not free of its obsessive ranking and sorting," echoing the modern-day suspicion of "acceptable" identities, the ways in which the subordinated come to mirror the dominant (p. 85). What are the culturally authorized stories we tell about queer identity, the mythologies of gender and desire that sanitize gender or desire?

It is, finally, a transition memoir, though less about a singular transition moment than about being trans without being trans, disinterested in emotional trauma or perfect narratives which idealize and solidify heterosexual matrices. If you're expecting a history of pain and discomfort, you will find it; not emotional, but rather physical, the pain and discomfort of anal sex translates the fetishized emotional pain of transition narratives into graphic physical pleasure, the author's clawing-at-the-skin to mold it, to invert it. Queering queer narratives is especially important in a culture that continually sanctions identity within dominant narratives: not everyone knows they're trans, or knows they're trans in childhood, for instance. "Story," as Wark warns us, "is a ruse of memory" (p. 173). 
Readers of Wark's I'm Very into You: Correspondence 1995-1996 (2015) may find a similar symposia, discursive tchotchkes, dialogue chapters, stageless plays, which interrupt Wark's narrative to magnify life in media res. "Penetration" memorializes pillow-talk between Wark and Edward-from whom Wark learned to be fucked, to be fuckable: "When you fuck me I don't think about my dick" (p. 83). Another, "Unidentified Flying Chicken," recounts an email exchange between Wark and writer Chris Kraus, a reflection on Wark's own turning-out as an émigré from Australia to the U.S., from broke college slut (a term the author relishes) to New York professor, and from man to woman. It is - oddly, vicariously - voyeuristic, and the intimate nature of each communiqué leaves one feeling invited where they should not be.

However, the euphoric climax ruins the wondrous unspeakability that actuates that being. Wark bisects her work into Orpheus Speaks and Eurydice Speaks, a division that I found undermined its predominant ambience of nonexistence. At once, Wark's memoir rails against this tempting revisionist narrative and yet succumbs to it. This familiar epiphany of the alternately gendered self curtails the mounting specter of change: that it is less a flowering than a deflowering, less a realization of presence than a congealization of absence. I can't help but feel in every one of Wark's transitions the wisp of success-strange for an autoethnography so absorbed with failure.

Yet Reverse Cowgirl is not at a loss for style. Wark playfully juxtaposes the rituals of fucking and academia (without making you scream, "fucking academia!"). Wark presses Leslie, the extravagant top, against Bini Adamczak's circlusion to undermine the power dynamics of penetration (p. 41). In "(How To) Get Yourself Fucked," Wark counters Jonathan Kemp's optimistic critique of the penetrated male body, pinning her fuckable body to femininity and femininity to objecthood. Wark writes at her best in that productive dissonance between the academic and the visceral personal lives we lead.

Can we locate Wark's work in an academic field? The ethnographic (and graphic) narrative speaks much to the late 20th Century transition of sexuality as what one does to what one is. A transnational's cross-section of the 80s, this text could easily find a home in queer studies, cultural studies, oral history, anthropology, sociology; however, I fear if it finds a home, it'll be on the optional readings list in some non-fiction course. I would rather it keep moving, a fellow traveler always circling disciplines, never taking root. That academic transience-Reverse Cowgirl's ability to pass through to diffuse disciplines and genres-could do much to dissolve the coagulated boundaries between them.

\section{Cite this Review}

Inscoe, J. "Reverse Cowgirl by McKenzie Wark." Rhizomes: Cultural Studies in Emerging Knowledge, no. 36, 2020, doi:10.20415/rhiz/036.r06

RHIZOMES ISSN 1555-9998 ^ 230 East Hall Bowling Green State University Bowling Green, OH 43403

Editors: Ellen Berry and Carol Siegel. Reviews editor: Craig J. Saper. Technical editor: Helen J Burgess 